\title{
Developing skills for thoracic aortic surgery with hypothermic circulatory arrest
}

Amine Mazine, MD, MSc, ${ }^{a}$ Louis-Mathieu Stevens, MD, PhD, FRCSC, ${ }^{b}$

Aly Ghoneim, MD, ${ }^{\mathrm{c}}$ Jennifer Chung, MD, MSc, FRCSC, ${ }^{\mathrm{d}}$ Maral Ouzounian, MD, PhD, FRCSC,

Francois Dagenais, MD, FRCSC, ${ }^{\mathrm{e}}$ Ismail El-Hamamsy, MD, PhD, FRCSC,

Munir Boodhwani, MD, MMSc, FRCSC, ${ }^{\mathrm{f}}$ John Bozinovski, MD, MSc, FRCSC, ${ }^{\mathrm{g}}$

Mark D. Peterson, MD, PhD, FRCSC, ${ }^{\text {and }}$ aichael W. A. Chu, MD, FRCSC, ${ }^{\text {i }}$ the Canadian Thoracic

Aortic Collaborative Investigators

\section{ABSTRACT}

Objectives: To examine the performance curves of 8 early-career aortic surgeons with the use of hypothermic circulatory arrest (HCA) and to analyze the impact of the learning curve on perioperative outcomes.

Methods: A total of 1025 consecutive patients who underwent aortic reconstruction with HCA between 2002 and 2017 were analyzed for mortality and 5 other complications (stroke, reoperation for bleeding, dialysis, prolonged ventilation, and sternal wound complications), subdivided into 3 consecutive time periods. This cohort represents the complete inaugural experience of 8 Canadian academic aortic surgeons. A risk-adjusted cumulative sum analysis was used to evaluate the performance curve with respect to predetermined $80 \%$ alert and $95 \%$ alarm boundary lines.

Results: Mean age was $62 \pm 13$ years, $71 \%$ of patients were male, and $24 \%$ presented nonelectively. Hemiarch repair was performed in $80 \%$ and total arch replacement in $20 \%$. There was a reduction in the incidence of the primary composite outcome over time (P1: 26\%, P2: 23\%, and P3: 16\%; $P=.010$ ). Overall in-hospital mortality was $5 \%$ and remained stable throughout the 3 periods. Rates of stroke were lower in the late period (P1: 4\%, P2: 6\%, and P3: $2 \% ; P=.035$ ). Risk-adjusted cumulative sum analysis demonstrated that all surgeons remained within the $95 \%$ reassurance boundary throughout their experience, with 6 surgeons performing as expected and 2 performing better than expected.

Conclusions: Early-career surgeons can safely perform operations with HCA from the initiation of their practice. The cumulative sum analysis method is valuable for monitoring competence in aortic surgery and could prove useful in structuring training programs. (J Thorac Cardiovasc Surg 2019;157:1360-8)

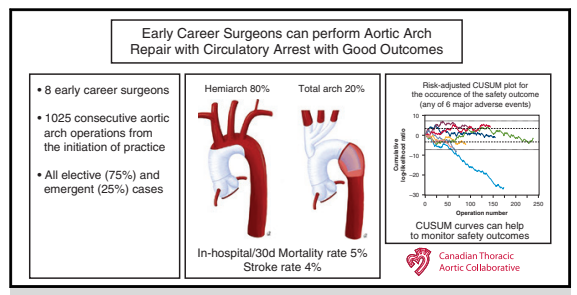

Early-career surgeons can safely perform aortic arch repair with circulatory arrest with good outcomes. Graphical abstract presenting characteristics of the study cohort and results of the CUSUM analysis.

\section{Central Message}

Early-career surgeons can safely perform aortic operations with hypothermic circulatory arrest from the initiation of their practice. The CUSUM analysis method is valuable for monitoring competence in aortic surgery.

\section{Perspective}

Several studies have investigated the relationship between institutional volumes and outcomes following aortic surgery. However, few have examined individual surgeons' performance. We found variability in the performance curves of 8 early-career surgeons performing operations with hypothermic circulatory arrest. However, all surgeons remained within the $95 \%$ reassurance boundary throughout their experience.

See Commentary on page 1369.

\footnotetext{
From the ${ }^{\mathrm{a}}$ Division of Cardiac Surgery, Department of Surgery, University of Toronto, Toronto, Ontario, Canada; ${ }^{b}$ Division of Cardiac Surgery, Department of Surgery, Centre Hospitalier Universitaire de Montréal and Université de Montréal, Montreal, Quebec, Canada; ${ }^{c}$ Division of Cardiac Surgery, Department of Surgery, Montreal Heart Institute and Université de Montréal, Montreal, Quebec, Canada; ${ }^{\mathrm{d}}$ Division of Cardiac Surgery, Department of Surgery, Toronto General Hospital and University of Toronto, Toronto, Ontario, Canada; ${ }^{\mathrm{e}}$ Division of Cardiac Surgery, Department of Surgery, Institut universitaire de cardiologie et de pneumologie de Québec and Université Laval, Quebec City, Quebec, Canada; ${ }^{\mathrm{f}}$ Division of Cardiac Surgery, Department of Surgery, Ottawa Heart Institute and University of Ottawa, Ottawa, Ontario, Canada; ${ }^{g}$ Division of Cardiac Surgery, Department of Surgery, Royal Jubilee Hospital and University of British Columbia, Victoria, British Columbia, Canada; ${ }^{\mathrm{h}}$ Division of Cardiac Surgery, Department of Surgery, St Michael's Hospital and University of Toronto, Toronto, Ontario, Canada; and i Divi-
}

sion of Cardiac Surgery, Department of Surgery, London Health Sciences Center and University of Western Ontario, London, Ontario, Canada.

Read at The American Association for Thoracic Surgery Aortic Symposium 2018, New York, New York, April 26-27, 2018.

Received for publication May 10, 2018; revisions received Nov 13, 2018; accepted for publication Nov 22, 2018; available ahead of print Jan 18, 2019.

Address for reprints: Michael W.A. Chu, MD, FRCSC, Division of Cardiac Surgery, Department of Surgery, University of Western Ontario, London Health Sciences Center, P.O. Box 5339, 339 Windermere Rd, B6-106 University Hospital, London, Ontario N6A 5A5, Canada (E-mail: michael.chu@lhsc.on.ca). $0022-5223 / \$ 36.00$

Copyright (c) 2018 by The American Association for Thoracic Surgery https://doi.org/10.1016/j.jtcvs.2018.11.110 
Abbreviations and Acronyms

$\mathrm{ACP}=$ antegrade cerebral perfusion

CUSUM $=$ cumulative sum

HCA $=$ hypothermic circulatory arrest

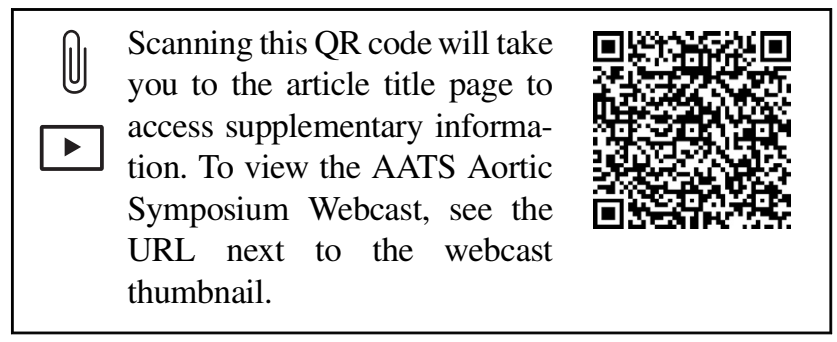

Deep hypothermia with circulatory arrest was introduced in the $1970 \mathrm{~s}^{1}$ and remains the approach of choice for a variety of aortic procedures. Although operations performed with the use of hypothermic circulatory arrest (HCA) span a broad spectrum of complexity, it is widely held that these procedures are technically demanding and associated with increased surgical risk. One of the main potential drawbacks for adopting any complex operation is the inherent learning curve. In this age of increased scrutiny and individual surgeon reporting, the issue of the learning curve is of great relevance, especially for early-career surgeons. Quality control metrics of nationally published databases focus heavily on perioperative outcomes. This raises questions about the feasibility and safety of starting an HCA program, particularly for surgeons in the early stages of their practice.

Several studies have investigated the relationship between institutional volumes and outcomes following aortic surgery, demonstrating an association between greater volumes and improved outcomes. ${ }^{2-4}$ However, few have examined individual surgeons' performance. Herein, we analyze the performance of 8 early-career aortic surgeons with the use of HCA across a spectrum of aortic reconstructive procedures. The aim of this study was to analyze the impact of the learning curve on short-term outcomes following aortic operations requiring HCA.

\section{METHODS}

\section{Study Population}

Between May 2002 and November 2017, a total of 1025 consecutive patients (mean age $62 \pm 13$ years) underwent surgery with the use of HCA across 7 centers participating in the Canadian Thoracic Aortic Collaborative. This cohort represents the inaugural experience of 8 academic aortic surgeons who started their respective aortic practices between 2002 and 2014. Patients who underwent thoracoabdominal aortic aneurysm repair were excluded from the present analysis. Cases were performed independently from one operator to another, such that the individual performance curves are not transposable. The total number of aortic cases performed yearly with HCA by each surgeon is presented in Figure 1. The study was approved by the local ethics committee at each institution, and a waiver of consent was obtained.

\section{Outcomes and Data Analysis}

Baseline characteristics, surgical details, and early outcomes were retrospectively collected through chart review using a standardized data collection form. The primary safety outcome was a composite endpoint that included death and 5 other perioperative adverse events: stroke, bleeding requiring re-exploration, acute renal failure requiring dialysis, long duration of postoperative mechanical ventilation ( $>40$ hours), and mediastinitis/sternal dehiscence. In addition, other adverse events (eg, myocardial infarction, atrial fibrillation, spinal cord injury, septic shock), blood product transfusion, as well as intensive care unit and hospital lengths of stay were analyzed as secondary outcomes.

Risk-adjusted cumulative sum (CUSUM) analyses were used to assess individual surgeon performance with respect to the primary safety outcome. Subgroup analyses were performed to compare the performance curves for hemiarch replacement versus total arch replacement, as well as for elective versus nonelective surgery. In addition, temporal trends for the occurrence of the primary safety outcome and secondary outcomes were analyzed by chronologically dividing each surgeon's cohort into thirds (ie, total number of cases divided by 3 ), and then pooling these thirds together. As such, each surgeons' learning experience is evenly proportioned within all 3 periodic groups.

\section{Statistical Analysis}

Continuous variables are expressed as mean \pm standard deviation or median [interquartile range] and were compared using analysis of variance with a $\log$ transformation for non-normally distributed variables. Categorical variables are expressed as frequencies (\%) and were compared using the Pearson $\chi^{2}$ test or Fisher's exact test, as appropriate. The Tukey adjustment was used for multiple comparisons. Statistical significance was set at $\alpha=0.05$.

Unadjusted and risk-adjusted CUSUM analyses were performed for the primary safety outcome for each surgeon using the method described by Rogers and colleagues. ${ }^{5}$ To summarize in brief, for each curve, acceptable (p0) and unacceptable (p1) complication rates were determined for the safety outcome. For the unadjusted curves, p0 was defined as the average incidence of the composite safety endpoint across the entire cohort. As such, "p0" was set at $32.5 \%$ for the full cohort, $30.1 \%$ for hemiarch cases, $42.3 \%$ for total arch cases, $48.0 \%$ for urgent cases, and $27.5 \%$ for elective cases. For the risk-adjusted curves, "p0" was defined as the predicted probability of incidence of the composite endpoint. This predicted probability was calculated for each patient using a multivariable logistic regression model (Table E1). Least absolute shrinkage and selection operator selection methods were used to identify candidate variables for the multivariable model. ${ }^{6}$ For all adjusted and unadjusted curves, "p1" was calculated by setting the odds ratio between "p0" and "p1" at 1.5 ( $50 \%$ increase in the odds ratio).

Using the aforementioned method, "p1" is static for unadjusted curves but variable for risk-adjusted curves, hence the need to present data on the log-likelihood scale. As such, cumulative log-likelihood ratio test charts and risk-adjusted sequential probability ratio test charts were used to present unadjusted and risk-adjusted CUSUM curves, respectively. In both cases, crossing of the upper boundary demonstrated a failure rate significantly greater than the unacceptable rate (p1) (ie, surgeon performing worse than expected), whereas a CUSUM curve inferior to the lower boundary indicated a failure rate lower than the acceptable rate (p0) (ie, surgeon performing better than expected). A CUSUM curve between the 2 boundaries was indicative of a lack of statistical significance (ie, surgeon performing as expected). Statistical analyses were performed using SAS 9.4 (SAS Institute, Cary, NC).

\section{RESULTS}

\section{Baseline Characteristics}

Baseline patient characteristics are summarized in Table 1. In general, baseline patient characteristics 


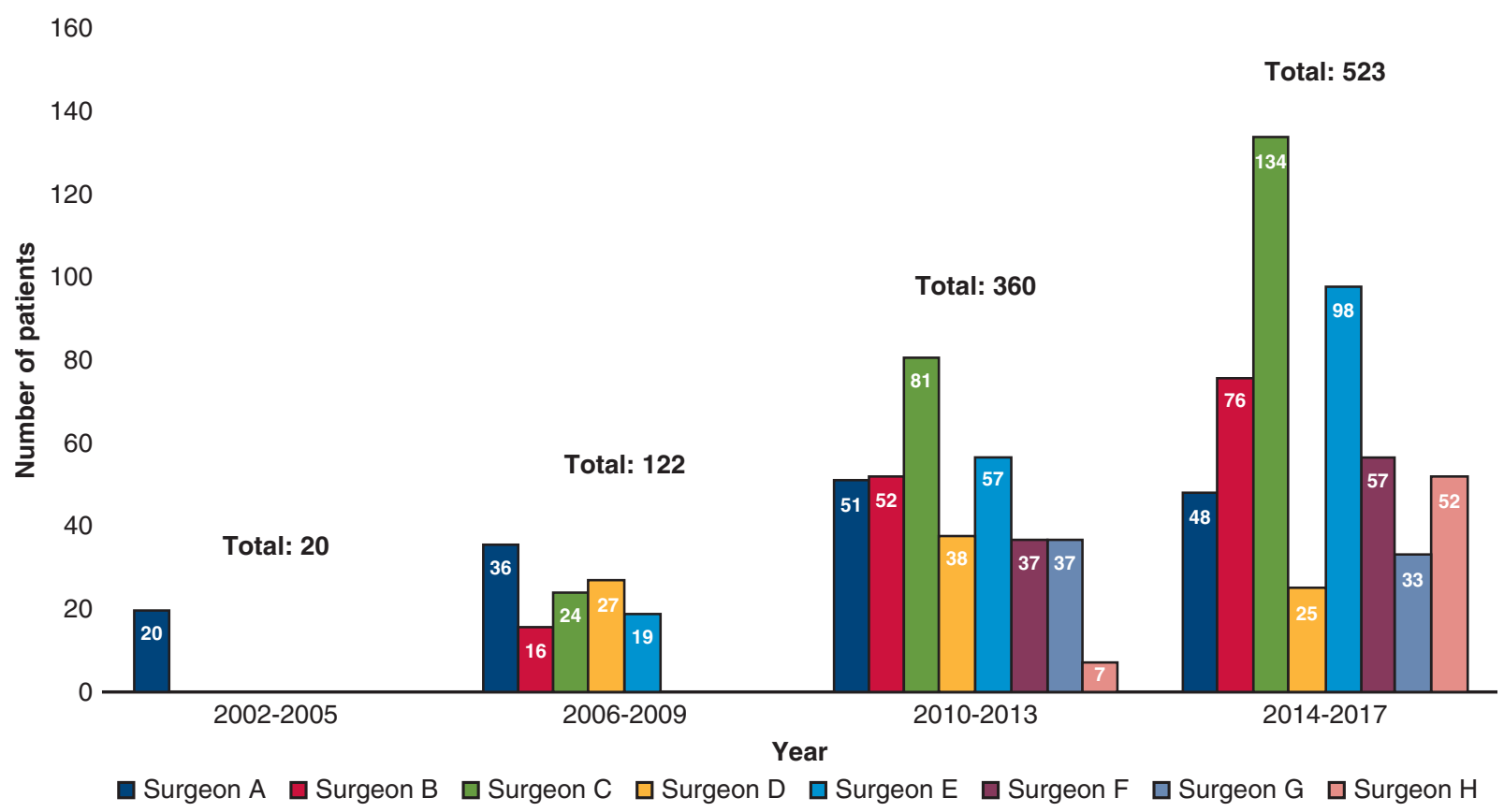

FIGURE 1. Distribution of cases performed by each surgeon over time.

remained stable throughout the study period (Table E2). Chronic obstructive pulmonary disease was less prevalent in the late period $(P=.028)$. There was a greater proportion of patients presenting with aortic aneurysms $(P=.005)$ and, reciprocally, a lower proportion presenting with aortic dissection $(P=.013)$ during the late period. Patients underwent surgery at a slightly lower mean aortic diameter during the intermediate and late periods. The prevalence of concomitant aortic insufficiency was greater during the late period $(P<.001)$. Overall, 151 patients $(15 \%)$ had undergone previous cardiac surgery. A bicuspid aortic valve was present in 321 patients $(32 \%)$. A greater proportion of patients presented electively during the late period as compared with the early period $(P=.044)$. Differences in baseline characteristics between patients operated by each of the 8 participating surgeons are presented in Table E3.

\section{Operative Details}

Operative details are presented in Table 2. There were significant changes over time (Table E4). Concomitant aortic valve replacement $(P=.045)$ and valve-sparing root replacement $(P=.005)$ were performed more frequently in the late period. Cannulation and perfusion strategies evolved over time. Axillary cannulation was performed less frequently in the later part of the experience, in favor of innominate artery cannulation $(P<.001)$. Surgeons were also more likely to perfuse through an elephant trunk graft in the intermediate and late periods, as compared with the early period $(P<.001)$. There was a temporal trend toward lesser degrees of hypothermia over time with a median nadir HCA temperature of $20^{\circ} \mathrm{C}$ in the early period versus $25^{\circ} \mathrm{C}$ in the intermediate and late periods $(P<.001)$. Selective antegrade cerebral perfusion (ACP) was commonly used by 7 surgeons from the onset of their experience and routinely by all 8 surgeons in the late period. There was a decrease in the median duration of HCA in the late period, as compared with the early period $(P=.029)$. Differences in operative details between patients operated by each of the 8 participating surgeons are presented in Table E5.

\section{Perioperative Outcomes}

Perioperative outcomes are presented for the entire cohort in Table 3, and for each period in Table E6. Overall in-hospital mortality was $5 \%$ and remained stable throughout all 3 time periods. With growing experience, there was a reduction in the incidence of the primary outcome (ie, $\geq 1$ major complications) from $26 \%$ in the early period to $23 \%$ in the intermediate period to $16 \%$ in the late period $(P=.010)$. This reduction was primarily driven by lower rates of stroke $(P=.035)$ and prolonged mechanical ventilation $(P=.001)$ in the late period. No difference was observed for the incidence of the 4 other complications that composed the primary safety outcome. Analysis of secondary endpoints revealed reductions in the rates of postoperative atrial fibrillation $(P=.017)$, transient ischemic attack $(P=.034)$, and delirium $(P=.005)$. With increasing experience, there was also a reduction in the use of all blood products. Median intensive care unit $(P=.002)$ and hospital $(P=.006)$ lengths of stay were shorter in the late period. Differences in perioperative 
TABLE 1. Baseline patient characteristics

\begin{tabular}{|c|c|}
\hline & Total $(n=1025)$ \\
\hline Age, $y$, mean \pm SD & $62 \pm 13$ \\
\hline Female sex & $301(29 \%)$ \\
\hline Body mass index, $\mathrm{kg} / \mathrm{m}^{2}$, mean $\pm \mathrm{SD}$ & $28 \pm 5$ \\
\hline NYHA class III or IV & $244(24 \%)$ \\
\hline LVEF $<40 \%$ & $60(6 \%)$ \\
\hline Previous cardiac surgery & $151(15 \%)$ \\
\hline \multicolumn{2}{|l|}{ Risk factors, $(\%)$} \\
\hline Smoking & $408(40)$ \\
\hline Hypertension & $710(69)$ \\
\hline Diabetes mellitus & $114(11)$ \\
\hline Dyslipidemia & $501(49)$ \\
\hline \multicolumn{2}{|l|}{ Comorbidities, $(\%)$} \\
\hline Coronary artery disease & $222(22)$ \\
\hline Previous myocardial infarction & $72(7)$ \\
\hline Congestive heart failure & $92(10)$ \\
\hline Atrial fibrillation & $136(13)$ \\
\hline Peripheral vascular disease & $100(10)$ \\
\hline History of stroke & $52(5)$ \\
\hline History of TIA & $47(5)$ \\
\hline Any cerebrovascular disease & $102(10)$ \\
\hline History of chronic renal disease & $103(10)$ \\
\hline COPD & $127(12)$ \\
\hline Connective tissue disorder* & $45(4)$ \\
\hline \multicolumn{2}{|l|}{ Thoracic aortic pathology, $(\%) \dagger$} \\
\hline Aortic aneurysm & $900(88)$ \\
\hline Aortic dissection & $228(22)$ \\
\hline Aortic rupture & $32(3)$ \\
\hline Maximum aortic diameter, $\mathrm{mm}$, mean $\pm \mathrm{SD}$ & $55 \pm 10$ \\
\hline \multicolumn{2}{|l|}{ Aortic valve pathology, $(\%) \dagger$} \\
\hline Aortic stenosis & $288(28)$ \\
\hline Aortic insufficiency $\ddagger$ & $200(20)$ \\
\hline \multicolumn{2}{|l|}{ Morphology } \\
\hline Tricuspid & $680(67)$ \\
\hline Bicuspid & $321(32)$ \\
\hline Unicuspid & $12(1)$ \\
\hline \multicolumn{2}{|l|}{ Presentation status, $(\%)$} \\
\hline Elective & $773(75)$ \\
\hline Urgent & $83(8)$ \\
\hline Emergent & $155(15)$ \\
\hline Salvage & $14(1)$ \\
\hline
\end{tabular}

$S D$, Standard deviation; $N Y H A$, New York Heart Association; $L V E F$, left ventricular ejection fraction; TIA, transient ischemic attack; $C O P D$, chronic obstructive pulmonary disease. *Genetically confirmed. †Not mutually exclusive. $\ddagger$ Greater than mild.

outcomes between patients operated by each of the 8 participating surgeons are presented in Table E7.

\section{CUSUM Analyses of Safety Outcomes}

The mean number of aortic cases with HCA performed per surgeon per year-starting with the first complete year in practice-was 14 and ranged from 9 to 26. CUSUM analysis showed variability in the performance curves of the 8 participating surgeons (Figure 2). Unadjusted curves
TABLE 2. Operative details

\begin{tabular}{|c|c|}
\hline & Total $(n=1025)$ \\
\hline \multicolumn{2}{|l|}{ Thoracic aortic procedure, $(\%)^{*}$} \\
\hline Hemiarch replacement & $818(80)$ \\
\hline Total arch replacement & $201(20)$ \\
\hline Elephant trunk & $134(13)$ \\
\hline \multicolumn{2}{|l|}{ Aortic valve and/or root procedure, $(\%)^{*}$} \\
\hline Aortic valve replacement & $178(17)$ \\
\hline Biological & $129(13)$ \\
\hline Mechanical & $49(5)$ \\
\hline Bentall procedure & $333(32)$ \\
\hline Biological & 199 (19) \\
\hline Mechanical & $134(13)$ \\
\hline Aortic valve repair & 199 (19) \\
\hline Valve-sparing root replacement & $124(12)$ \\
\hline Ross procedure & $33(3)$ \\
\hline Sinus root repair & $80(8)$ \\
\hline \multicolumn{2}{|l|}{ Concomitant procedures, $(\%)^{*}$} \\
\hline CABG & $203(20)$ \\
\hline Mitral valve repair & $25(2)$ \\
\hline Mitral valve replacement & $13(1)$ \\
\hline ASD/VSD repair & $12(1)$ \\
\hline Other concomitant procedures & $89(8)$ \\
\hline \multicolumn{2}{|l|}{ Arterial cannulation, $(\%)^{*}$} \\
\hline Femoral & $64(6)$ \\
\hline Axillary & $550(54)$ \\
\hline Innominate & $311(30)$ \\
\hline Carotid & $7(1)$ \\
\hline Distal arch & $157(15)$ \\
\hline Elephant trunk graft & $125(12)$ \\
\hline \multicolumn{2}{|l|}{ Perfusion details } \\
\hline CPB time, min, median [IQR] & $166[127,220]$ \\
\hline Aortic crossclamp time, min, median [IQR] & $117[79,163]$ \\
\hline HCA duration, min, median [IQR] & $20[13,29]$ \\
\hline Long HCA duration ( $>40 \mathrm{~min}$ ) & $145(14 \%)$ \\
\hline HCA lowest temperature, ${ }^{\circ} \mathrm{C}$, median $[\mathrm{IQR}]$ & $24[20,26]$ \\
\hline \multicolumn{2}{|l|}{ Cerebral perfusion, $(\%)$} \\
\hline None & $98(10)$ \\
\hline Antegrade & 909 (89) \\
\hline Retrograde & $18(2)$ \\
\hline
\end{tabular}

$C A B G$, Coronary artery bypass grafting; $A S D$, atrial septal defect; $V S D$, ventricular septal defect; $C P B$, cardiopulmonary bypass; $I Q R$, interquartile range; $H C A$, hypothermic circulatory arrest. *Not mutually exclusive.

(Figure 2, A) demonstrated that 5 of 8 surgeons remained between the reassurance and alarm boundaries throughout their experience (ie, performed as expected), 2 surgeons eventually crossed the $95 \%$ reassurance boundary line (ie, performed better than expected), whereas 1 surgeon persistently remained above the $95 \%$ alert boundary line (ie, performed worse than expected). However, when we adjusted for baseline patient characteristics, all surgeons remained within the $95 \%$ reassurance boundary throughout their experience, with 6 surgeons performing as expected and 2 performing better than expected (Figure 2, B). Among surgeons who crossed the reassurance line, improvements 
TABLE 3. Perioperative outcomes

\begin{tabular}{lc}
\hline & Total $(\mathbf{n}=\mathbf{1 0 2 5})$ \\
\hline Primary safety outcome, $(\%)$ & \\
$\geq 1$ major complications* & $221(22)$ \\
In-hospital or 30-d mortality & $54(5)$ \\
Stroke & $44(4)$ \\
Reoperation for bleeding & $87(8)$ \\
Dialysis-dependent renal failure & $36(4)$ \\
$>40$ h of mechanical ventilation & $107(10)$ \\
Sternal dehiscence/mediastinitis & $10(1)$ \\
Other adverse events, $(\%)$ & \\
Myocardial infarction & $15(1)$ \\
Postoperative IABP requirement & $2(0)$ \\
Postoperative atrial fibrillation & $375(37)$ \\
Cardiac arrest/malignant arrhythmia & $30(3)$ \\
Spinal cord injury & $9(1)$ \\
Transient ischemic attack & $18(2)$ \\
Delirium & $198(19)$ \\
Septic shock & $14(1)$ \\
Blood product transfusion, (\%) & \\
Packed red blood cells & $352(34)$ \\
Fresh-frozen plasma & $441(43)$ \\
Platelets & $458(45)$ \\
Factor VII & $62(6)$ \\
ICU length of stay, d, median $[\mathrm{IQR}]$ & $2[1,4]$ \\
ICU length of stay $\geq 4 \mathrm{~d}$ & $272(27 \%)$ \\
Hospital length of stay, d, median $[\mathrm{IQR}]$ & $7[5,12]$ \\
\hline
\end{tabular}

$I A B P$, Intra-aortic balloon pump; $I C U$, intensive care unit; $I Q R$, interquartile range. * Major complications defined as the occurrence of at least 1 of the following: death, stroke, bleeding requiring re-exploration, acute renal failure requiring dialysis, long duration of postoperative mechanical ventilation ( $>40$ hours), and sternal dehiscence/mediastinitis.

in outcomes were seen after $\sim 50$ to 70 cases. Of note, following risk adjustment, 1 of the surgeons who was performing better than expected on the unadjusted curves performed as expected, whereas a different surgeon who was performing as expected on the unadjusted analysis performed better than expected.

When considering only hemiarch repairs (with risk adjustment), findings were similar, albeit with earlier crossing of the $95 \%$ reassurance line ( $\sim 50$ cases) for the 2 surgeons performed better than expected (Figure 3, A). The remaining 6 surgeons performed as expected throughout their experience. In contrast, only 1 of 8 surgeons crossed the $95 \%$ reassurance line on the risk-adjusted total arch replacement CUSUM curve (Figure 3, B). Importantly, all surgeons remained within the $80 \%$ reassurance boundary throughout their experience with total arch replacement. Similarly, when stratifying by case urgency, all surgeons remained within the reassurance boundary throughout their experience with elective cases (Figure 4, A), with 2 of 8 surgeons eventually crossing the $95 \%$ reassurance boundary. Finally, for nonelective cases (Figure $4, B$ ), only 1 of 8 surgeons crossed the 95\%
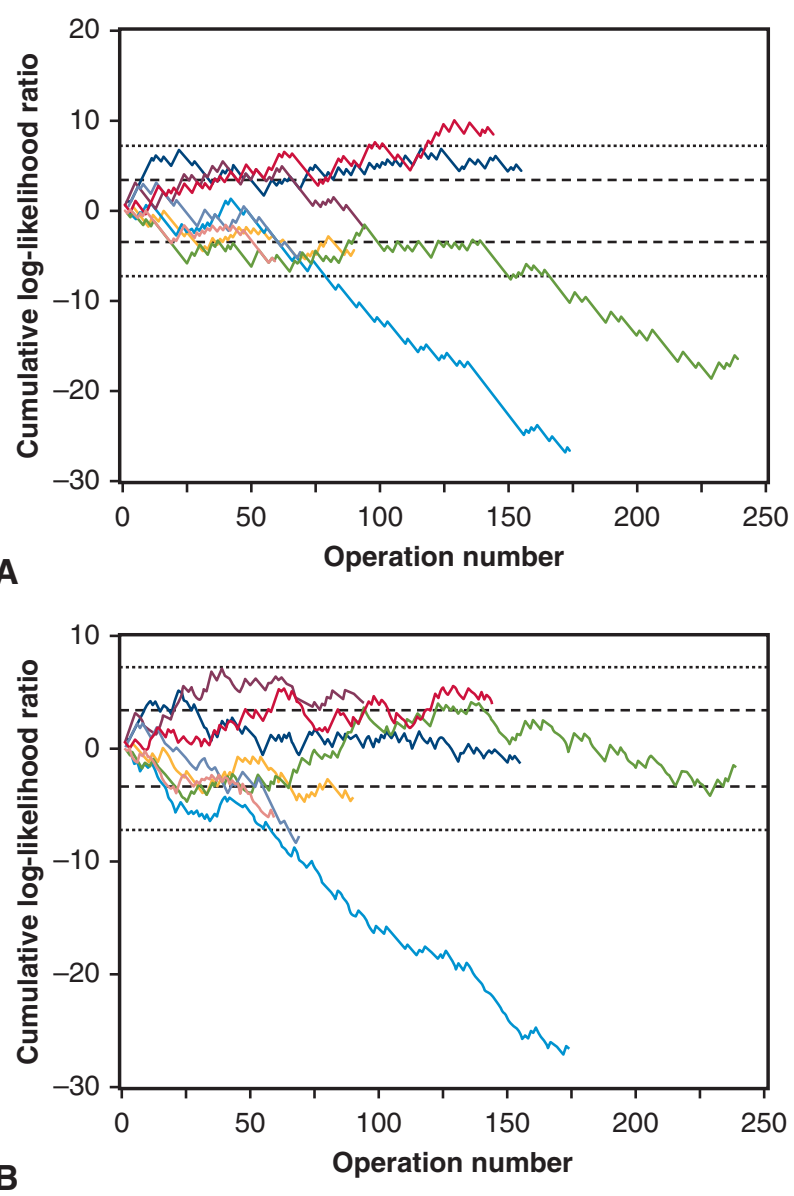

FIGURE 2. Overall performance curve for aortic reconstruction with hypothermic circulatory arrest. Unadjusted (A) and risk-adjusted (B) cumulative sum plot for the occurrence of the safety outcome (any of 6 major adverse events) during aortic reconstruction with hypothermic circulatory arrest in the entire cohort. Each colored line represents a different surgeon's learning curve. Dashed lines: $80 \%$ alert (top) and reassurance (bottom) lines. Dotted lines: 95\% alarm (top) and reassurance (bottom lines).

reassurance line, whereas 1 surgeon crossed the $80 \%$ alert line. No correlation was observed between the total or annual volume of nonelective cases performed and crossing of the reassurance/alert boundary lines. However, there was a single surgeon who consistently crossed the $95 \%$ risk-adjusted reassurance line (ie, performed better than expected) across all subgroups, and this surgeon had the second-greatest annual and total case volume.

\section{DISCUSSION}

This study sought to assess the performance of early-career surgeons with the use of HCA within a comprehensive aortic program. The main findings are that HCA can be used safely in a wide variety of elective and nonelective aortic operations, including by surgeons in their first years of practice (Video 1). After we adjusted for 

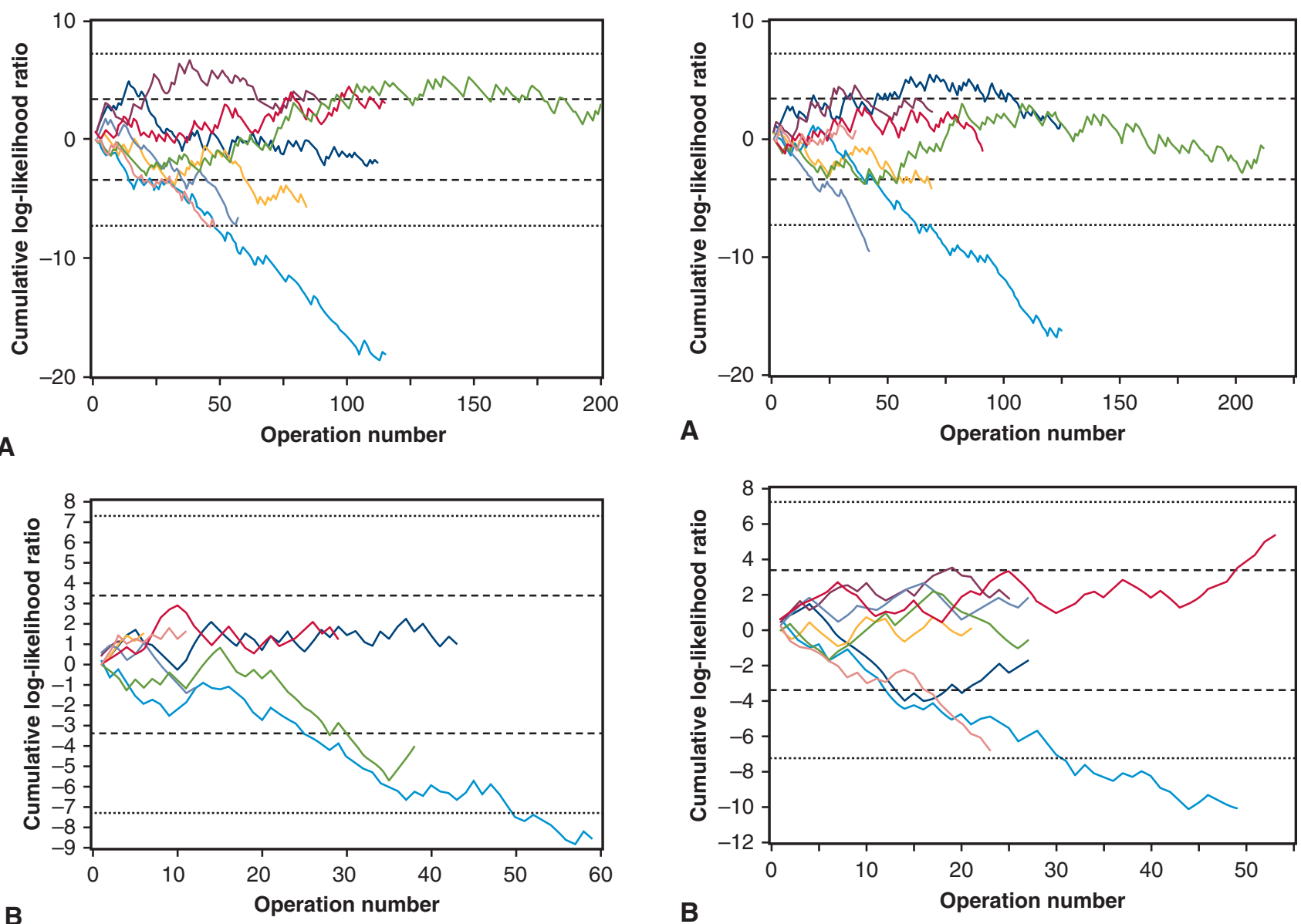

FIGURE 3. Learning curve for aortic reconstruction with hypothermic circulatory arrest stratified by extent of distal reconstruction. Risk-adjusted cumulative sum plot for the occurrence of the safety outcome (any of 6 major adverse events) during hemiarch replacement (A) and total arch replacement (B) with hypothermic circulatory arrest. Each colored line represents a different surgeon's learning curve. Dashed lines: $80 \%$ alert (top) and reassurance (bottom) lines. Dotted lines: 95\% alarm (top) and reassurance (bottom lines).

baseline patient risk, all surgeons performed as expected or better throughout their experience. Furthermore, this analysis allowed identification of an outlier who consistently performed better than expected, across all subgroups. Despite variability in individual performance, overall mortality and morbidity in this multicenter cohort from 8 early-career surgeons compare favorably with the published literature, including results from high-volume centers with established expertise in thoracic aortic surgery. ${ }^{7-12}$

Although there are some differences between the programs represented in this study, a common theme is that each of the participating surgeons is supported by a well-organized, multimodal program focused on the medical and surgical management of aortic diseases (ie, comprehensive aortic program). Characteristics of such programs include rigorous follow-up of patients at regularly

FIGURE 4. Learning curve for aortic reconstruction with hypothermic circulatory arrest stratified by procedure urgency. Risk-adjusted cumulative sum plot for occurrence of the safety outcome (any of 6 major adverse events) during elective (A) and nonelective (B) aortic reconstruction with hypothermic circulatory arrest. Each colored line represents a different surgeon's learning curve. Dashed lines: $80 \%$ alert (top) and reassurance (bottom) lines. Dotted lines: 95\% alarm (top) and reassurance (bottom lines).

scheduled intervals (including routine echocardiographic and computed tomography or magnetic resonance imaging), presence of a multidisciplinary aortic clinic-including geneticists, cardiologists, vascular surgeons, radiologists, etc —with a wide referral base (ie, cardiologists, general practitioners, radiologists, emergency physicians), and a therapeutic armamentarium spanning the gamut of open, endovascular, and hybrid aortic techniques. Furthermore, most of these aortic programs are not only active in clinical care but also have busy research activities. As a result, the aortic programs helped support these early-career surgeons with high volumes of carefully selected patients undergoing well-planned operations with careful patient follow-up.

All 8 surgeons participating in this study started performing operations with the use of HCA during their first year in practice, highlighting the notion that these operations can be 
performed reproducibly and safely early in an aortic surgeon's career, provided that a number of conditions are met. These conditions include proper training- 6 of the 8 participating surgeons had formal fellowship training in aortic surgeryadequate patient selection, satisfactory mentorship, and a sufficient volume of thoracic aortic operations. Of note, all participating surgeons practice in academic centers and were assisted by surgical trainees for the vast majority of cases. However, it is plausible that a senior, more experienced surgeon may have assisted on some of the greatest-risk cases. The correlation between surgical volumes and outcomes in cardiac surgery is now well established, particularly for thoracic aortic surgery. ${ }^{2,3,13}$ Hence, to mitigate the effects of the learning curve, surgeons should strive to perform a minimum number of these operations per year. In the present study, the mean number of aortic cases with HCA performed per surgeon per year-starting with the first complete year in practice-was 14 and ranged from 9 to 26 . Of note, the surgeon with the best performance curve was also the one with the second-greatest mean annual volume.

Although these findings are in keeping with the expanding body of evidence linking surgical outcomes to case volume, the number of surgeons included in the present study is too low to draw any definitive conclusions. Furthermore, although there were no notable differences in the performance the 2 surgeons without formal aortic fellowship training compared with the other 6 surgeons, no meaningful conclusions can be derived from the small number of surgeons included. In addition, it should be stressed that despite risk adjustment, residual differences in baseline patient characteristics, concomitant operations, and center expertise in the management of these patients may have contributed to the differences in outcomes observed between surgeons participating in this study.

The overall operative mortality in this series was 5\% (including elective and nonelective cases), which compares favorably with the published experience of established high-volume aortic centers, ${ }^{11,12}$ considering the fact that a high proportion of patients underwent complex concomitant procedures-such as aortic valve repair, valve-sparing root replacement, and the Ross procedureand that a quarter of patients presented nonelectively. Despite more extensive concomitant proximal aortic surgery in the late period, operative mortality remained stable throughout the study. This may be in part explained by the fact that a greater proportion of patients presented electively during the late period. The significant improvement observed in the primary composite outcome during the later stages of the study was mainly driven by lower rates of prolonged mechanical ventilation. This finding must be interpreted in light of the fact that fewer patients had coexisting chronic obstructive pulmonary disease during the late period.

There was an evolution in cannulation and cerebral-protection strategies over the course of the study.
Specifically, with increasing experience, there was a shift toward increased use of innominate artery cannulation, more frequent use of ACP, and a move toward more moderate degrees of hypothermia, despite the increase in overall operative complexity throughout the study periods. Indeed, although hypothermia is the cornerstone of neuroprotection during aortic arch surgery, the optimal core temperature and ideal mode of cerebral perfusion remain controversial. The shift from deep HCA to moderate HCA in this study is consistent with a wider trend observed in recent years. ${ }^{14-17}$ This shift in practice has been driven by a desire to mitigate the potential risk of severe coagulopathy associated with deep HCA, reduce cooling and rewarming times, and improve the overall operative efficiency.

Interestingly, over the course of this study, there was a significant decrease in rates of perioperative transfusions, which coincided with the shift from deep HCA to moderate HCA. Importantly, despite this shift toward lesser degrees of hypothermia, rates of spinal ischemia remained low and constant throughout the study periods, whereas the incidence of stroke decreased in the late period. These data suggest that moderate HCA may constitute a safe and effective alternative to deep HCA. However, this study was not designed to assess the impact of HCA temperature on the incidence of perioperative blood product transfusion, and any association observed should be interpreted as hypothesis-generating. Furthermore, the potential benefits derived from using lesser degrees of hypothermia must be balanced with the extent of surgery, predicted duration of $\mathrm{HCA}$, and adequate brain-protection strategies.

Another evolution in surgical strategy observed in this study was the increased use of ACP over time. This shift in practice also reflects a growing consensus in recent years toward favoring $\mathrm{ACP}$ over retrograde cerebral perfusion as an adjunct cerebral protection strategy. ${ }^{14,18-20}$ This trend has been facilitated by the increased use of axillary cannulation, which has progressively gained popularity over femoral cannulation for arterial inflow. ${ }^{19-24}$ More recently, innominate artery cannulation has been recognized as a simplified, reproducible, and safe alternative route for ACP. ${ }^{11,25,26}$ The majority of surgeons in the present study have been early adopters of this technique, as evidenced by the gradual shift away from axillary cannulation in favor of innominate cannulation over the course of the study.

The CUSUM method, which was originally pioneered in the field of congenital cardiac surgery, ${ }^{27}$ has since been applied to a variety of settings, such as minimally invasive coronary artery bypass grafting, ${ }^{28}$ minimally invasive mitral valve repair, ${ }^{29}$ the Ross procedure, ${ }^{30,31}$ and aortic valve repair. ${ }^{32}$ The study reported herein is the first to examine its use in thoracic aortic surgery with HCA. In addition, the present study is the largest published series reporting risk-adjusted CUSUM curves in the field of cardiothoracic surgery. Our findings highlight the 


\section{Early Career Surgeons can perform Aortic Arch \\ Repair with Circulatory Arrest with Good Outcomes}

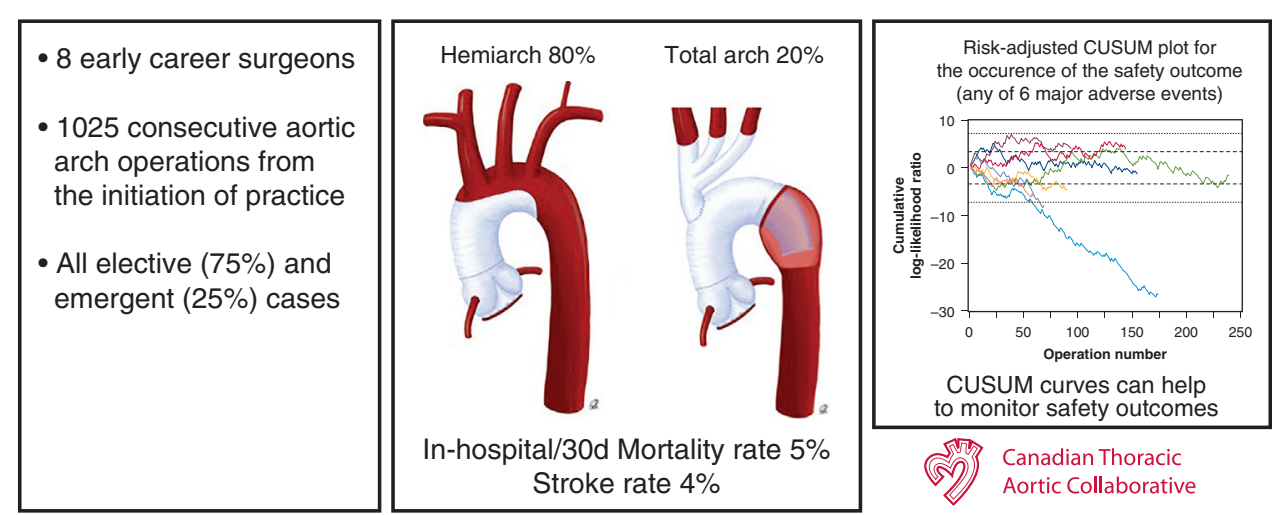

FIGURE 5. Summary of the study. Graphical abstract summarizing cohort characteristics (left panel), intraoperative details and perioperative outcomes (central panel), and risk-adjusted CUSUM analysis results (right panel). CUSUM, Cumulative sum.

importance of adjusting for baseline risk differences when comparing the performance of different surgeons. Indeed, 1 surgeon who was found to perform worse than expected on the unadjusted analysis, and another who was found to perform better than expected, both were found to perform as expected following risk adjustment.

The CUSUM analysis is a valuable method for monitoring individual surgeon performance. Unlike traditional retrospective audits-which only allow detection of outlying performance when the difference in outcomes has reached statistical significance-CUSUM analysis allows continuous monitoring and can quickly alert a surgeon to a deterioration in performance. As such, this analysis is particularly helpful for early-career surgeons attempting to monitor operative outcomes of patients undergoing aortic reconstruction with HCA. In addition, CUSUM analyses can be repeated as often as desired, providing an almost real-time monitoring of surgical performance.

The main limitation of this study is its retrospective, observational design. Despite a reasonable sample size, the incidence of many postoperative complications was low, making this study underpowered to detect subtle

\section{CUSUM Analysis}

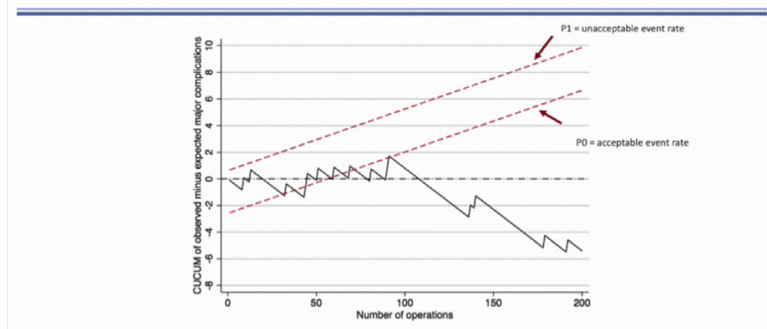

VIDEO 1. Summary of study design and main findings. Video available at: https://www.jtcvs.org/article/S0022-5223(18)33263-X/fulltext. differences in outcomes. Another limitation is the fact that not all surgeons performed equal number of cases. As such, a surgeon's "early" period may correspond-in terms of absolute volumes - to another surgeon's early and middle periods, for example. This study relied on internal standards-germane to the Canadian academic cardiac surgical environment-for risk adjustment and establishing acceptable performance. The use of external standards such as variables from the European System for Cardiac Operative Risk Evaluation II, national average values, or published results from expert centers in the field would have enhanced the generalizability of our findings. Finally, in the absence of established risk prediction scores for operations with HCA, the definition of what was considered an "acceptable" complication rate was by necessity somewhat arbitrary. Using more stringent boundary lines would have prolonged the learning curve. However, as the same criteria were applied consistently to the 8 participating surgeons, meaningful comparisons were still possible. These limitations notwithstanding, this large, multicenter study is the first to apply CUSUM methodology to the field of thoracic aortic surgery with HCA and represents a relevant addition to the current body of literature on surgical performance in cardiac surgery.

\section{CONCLUSIONS}

In conclusion, this study demonstrates that early-career surgeons can safely perform thoracic aortic operations with the use of HCA from the initiation of their practice (Figure 5). There is wide variability in individual surgeons' learning curves, but in a majority of cases, surgeons perform as expected throughout their experience. Overall operative mortality and incidence of adverse events compared favorably to published results from high-volume institutions with established expertise in thoracic aortic surgery. The CUSUM analysis 
method is valuable for monitoring competence in aortic surgery and could prove useful in structuring training programs.

\section{Webcast}

You can watch a Webcast of this AATS meeting presentation by going to: https://aats.blob.core.windows. net/media/18AO/26-br-1100-mazine-v2.mp4.

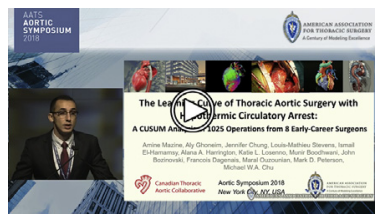

\section{Conflict of Interest Statement}

Authors have nothing to disclose with regard to commercial support.

We acknowledge the contributions of Alana A. Harrington and Katie Losenno, who participated in data collection for this study. We also thank Dr Éric Dumont, who contributed cases to this analysis. Finally, we thank all members of the Canadian Thoracic Aortic Collaborative (Table E8), who provided feedback on this study.

\section{References}

1. Barratt-Boyes B. Profound hypothermia-technical aspects. Singapore Med J. 1973;14:445-7.

2. Gazoni LM, Speir AM, Kron IL, Fonner E, Crosby IK. Elective thoracic aortic aneurysm surgery: better outcomes from high-volume centers. J Am Coll Surg. 2010;210:855-9. 859-60.

3. Miyata H, Motomura N, Ueda Y, Tsukihara H, Tabayashi K, Takamoto S. Toward quality improvement of thoracic aortic surgery: estimating volume-outcome effect from nationwide survey. Eur J Cardiothorac Surg. 2009;36:517-21.

4. Hughes GC, Zhao Y, Rankin JS, Scarborough JE, O'Brien S, Bavaria JE, et al. Effects of institutional volumes on operative outcomes for aortic root replacement in North America. J Thorac Cardiovasc Surg. 2013;145:166-70.

5. Rogers CA, Reeves BC, Caputo M, Ganesh JS, Bonser RS, Angelini GD. Control chart methods for monitoring cardiac surgical performance and their interpretation. J Thorac Cardiovasc Surg. 2004;128:811-9.

6. Tibshirani R. Regression shrinkage and selection via the lasso. J R Stat Soc Ser B. 1996;58:267-88.

7. Achneck HE, Rizzo JA, Tranquilli M, Elefteriades JA. Safety of thoracic aortic surgery in the present era. Ann Thorac Surg. 2007;84:1180-5; discussion 1185.

8. Halkos ME, Kerendi F, Myung R, Kilgo P, Puskas JD, Chen EP. Selective antegrade cerebral perfusion via right axillary artery cannulation reduces morbidity and mortality after proximal aortic surgery. J Thorac Cardiovasc Surg. 2009;138:1081-9.

9. Olsson C, Eriksson N, Stahle E, Thelin S. Surgical and long-term mortality in 2634 consecutive patients operated on the proximal thoracic aorta. Eur J Cardiothorac Surg. 2007;31:963-9; discussion 969.

10. Tian DH, Wan B, Bannon PG, Misfeld M, LeMaire SA, Kazui T, et al. A meta-analysis of deep hypothermic circulatory arrest versus moderate hypothermic circulatory arrest with selective antegrade cerebral perfusion. Ann Cardiothorac Surg. 2013;2:148-58.

11. Preventza O, Garcia A, Tuluca A, Henry M, Cooley DA, Simpson K, et al. Innominate artery cannulation for proximal aortic surgery: outcomes and neurological events in 263 patients. Eur J Cardiothorac Surg. 2015;48:937-42; discussion 942.

12. Ziganshin BA, Rajbanshi BG, Tranquilli M, Fang H, Rizzo JA, Elefteriades JA. Straight deep hypothermic circulatory arrest for cerebral protection during aortic arch surgery: safe and effective. J Thorac Cardiovasc Surg. 2014;148:888-98; discussion 898-900.
13. Murzi M, Miceli A, Di Stefano G, Cerillo AG, Kallushi E, Farneti P, et al. Enhancing quality control and performance monitoring in thoracic aortic surgery: a 10-year single institutional experience. Eur J Cardiothorac Surg. 2015;47:608-15.

14. Gutsche JT, Ghadimi K, Patel PA, Robinson AR III, Lane BJ, Szeto WY, et al. New frontiers in aortic therapy: focus on deep hypothermic circulatory arrest. J Cardiothorac Vasc Anesth. 2014;28:1159-63.

15. Leshnower BG, Myung RJ, Kilgo PD, Vassiliades TA, Vega JD, Thourani VH, et al. Moderate hypothermia and unilateral selective antegrade cerebral perfusion: a contemporary cerebral protection strategy for aortic arch surgery. Ann Thorac Surg. 2010;90:547-54.

16. Leshnower BG, Myung RJ, Thourani VH, Halkos ME, Kilgo PD, Puskas JD, et al. Hemiarch replacement at 28 degrees $\mathrm{C}$ : an analysis of mild and moderate hypothermia in 500 patients. Ann Thorac Surg. 2012;93:1910-5; discussion 1915-6.

17. Peterson MD, Mazine A, El-Hamamsy I, Manlhiot C, Ouzounian M, MacArthur RG, et al. Knowledge, attitudes, and practice preferences of Canadian cardiac surgeons toward the management of acute type A aortic dissection. J Thorac Cardiovasc Surg. 2015;150:824-31.e821-5.

18. Ehrlich MP, Hagl C, McCullough JN, Zhang N, Shiang H, Bodian C, et al. Retrograde cerebral perfusion provides negligible flow through brain capillaries in the pig. J Thorac Cardiovasc Surg. 2001;122:331-8.

19. Appoo JJ, Bozinovski J, Chu MW, El-Hamamsy I, Forbes TL, Moon M, et al. Canadian Cardiovascular Society/Canadian Society of Cardiac Surgeons/ Canadian Society for Vascular Surgery Joint Position Statement on Open and Endovascular Surgery for Thoracic Aortic Disease. Can J Cardiol. 2016;32:703-13.

20. El-Hamamsy I, Ouzounian M, Demers P, McClure S, Hassan A, Dagenais F, et al. State-of-the-art surgical management of acute type A aortic dissection. Can J Cardiol. 2016;32:100-9.

21. Gulbins H, Pritisanac A, Ennker J. Axillary versus femoral cannulation for aortic surgery: enough evidence for a general recommendation? Ann Thorac Surg. 2007;83:1219-24.

22. Moizumi Y, Motoyoshi N, Sakuma K, Yoshida S. Axillary artery cannulation improves operative results for acute type A aortic dissection. Ann Thorac Surg. 2005; $80: 77-83$.

23. Reuthebuch O, Schurr U, Hellermann J, Pretre R, Kunzli A, Lachat M, et al. Advantages of subclavian artery perfusion for repair of acute type A dissection. Eur J Cardiothorac Surg. 2004;26:592-8.

24. Svensson LG, Blackstone EH, Rajeswaran J, Sabik JF III, Lytle BW, GonzalezStawinski G, et al. Does the arterial cannulation site for circulatory arrest influence stroke risk? Ann Thorac Surg. 2004;78:1274-84; discussion 1274-84.

25. Chu MW, Losenno KL, Gelinas JJ, Garg V, Dickson J, Harrington A, et al Innominate and axillary cannulation in aortic arch surgery provide similar neuroprotection. Can J Cardiol. 2016;32:117-23.

26. Garg V, Tsirigotis DN, Dickson J, Dalamagas C, Latter DA, Verma S, et al. Direct innominate artery cannulation for selective antegrade cerebral perfusion during deep hypothermic circulatory arrest in aortic surgery. I Thorac Cardiovasc Surg. 2014;148:2920-4

27. de Leval MR, Carthey J, Wright DJ, Farewell VT, Reason JT. Human factors and cardiac surgery: a multicenter study. J Thorac Cardiovasc Surg. 2000;119: 661-72.

28. Holzhey DM, Jacobs S, Walther T, Mochalski M, Mohr FW, Falk V. Cumulative sum failure analysis for eight surgeons performing minimally invasive direct coronary artery bypass. J Thorac Cardiovasc Surg. 2007;134:663-9.

29. Holzhey DM, Seeburger J, Misfeld M, Borger MA, Mohr FW. Learning minimally invasive mitral valve surgery: a cumulative sum sequential probability analysis of 3895 operations from a single high-volume center. Circulation. 2013; 128:483-91.

30. Stelzer P, Itagaki S, Varghese R, Chikwe J. Operative mortality and morbidity after the Ross procedure: a 26- year learning curve. J Heart Valve Dis. 2013; 22:767-75.

31. Bouhout I, Ghoneim A, Poirier N, Cartier R, Demers P, Perrault LP, et al. Impact of the learning curve on early outcomes following the Ross procedure. Can J Cardiol. 2017;33:493-500.

32. Malas T, Saczkowski R, Sohmer B, Ruel M, Mesana T, de Kerchove L, et al. Is Aortic valve repair reproducible? Analysis of the learning curve for aortic valve repair. Can J Cardiol. 2015;31:1497.e1415-22.

Key Words: performance curve, circulatory arrest, cumulative sum analysis 
TABLE E1. Multivariable analysis of factors associated with the composite safety endpoint

\begin{tabular}{lcc}
\hline \multicolumn{1}{c}{ Risk factors } & Odds ratio $(\mathbf{9 5} \%$ CI) & $\boldsymbol{P}$ value \\
\hline Age (per 10 y) & $1.40(1.24-1.58)$ & $<.001$ \\
\hline Female sex & $0.99(0.72-1.36)$ & .945 \\
\hline Body mass index & $0.92(0.77-1.09)$ & .342 \\
\hline History of CVD or PVD & $1.58(1.10-2.28)$ & .013 \\
\hline History of smoking or COPD & $1.54(1.16-2.05)$ & .003 \\
Emergent or salvage operation & $2.47(1.47-4.15)$ & $<.001$ \\
\hline Aortic dissection or rupture & $1.72(1.09-2.72)$ & .020 \\
Coronary artery disease & $1.48(1.04-2.11)$ & .030 \\
\hline Concomitant procedure & $1.36(0.99-1.86)$ & .056 \\
\hline Total arch replacement & $1.40(0.98-2.01)$ & .068 \\
\hline CI, Confidence interval; $C V D$, cerebrovascular disease; $P V D$, peripheral vascular \\
disease; $C O P D$, chronic obstructive pulmonary disease. &
\end{tabular}


TABLE E2. Baseline patient characteristics in each period

\begin{tabular}{|c|c|c|c|c|}
\hline & First third $(\mathrm{n}=339)$ & Second third $(n=344)$ & Third third $(n=342)$ & $P$ value* \\
\hline Age, $y$, mean \pm SD & $62 \pm 14$ & $63 \pm 13$ & $62 \pm 13$ & .503 \\
\hline Female sex & $101(30 \%)$ & $96(28 \%)$ & $104(30 \%)$ & .750 \\
\hline Body mass index, $\mathrm{kg} / \mathrm{m}^{2}$, mean $\pm \mathrm{SD}$ & $28 \pm 5$ & $28 \pm 5$ & $29 \pm 6$ & .005 \\
\hline NYHA class III or IV & $87(26 \%)$ & $83(24 \%)$ & $74(22 \%)$ & .458 \\
\hline LVEF $<40 \%$ & $17(5 \%)$ & $17(5 \%)$ & $26(8 \%)$ & .269 \\
\hline Previous cardiac surgery & $44(13 \%)$ & $53(15 \%)$ & $54(16 \%)$ & .534 \\
\hline \multicolumn{5}{|l|}{ Risk factors, $(\%)$} \\
\hline Smoking & $148(44)$ & $133(39)$ & $127(37)$ & .190 \\
\hline Hypertension & $231(68)$ & $245(71)$ & $234(68)$ & .628 \\
\hline Diabetes mellitus & $32(9)$ & $44(13)$ & $38(11)$ & .389 \\
\hline Dyslipidemia & $158(47)$ & $167(49)$ & $176(51)$ & .467 \\
\hline \multicolumn{5}{|l|}{ Comorbidities, $(\%)$} \\
\hline Coronary artery disease & $74(22)$ & $70(20)$ & $78(23)$ & .735 \\
\hline Previous myocardial infarction & $25(7)$ & $22(6)$ & $25(7)$ & .853 \\
\hline Congestive heart failure & $31(10)$ & $36(11)$ & $25(8)$ & .339 \\
\hline Atrial fibrillation & $49(14)$ & $45(13)$ & $42(13)$ & .745 \\
\hline Peripheral vascular disease & $32(9)$ & $34(10)$ & $34(10)$ & .973 \\
\hline History of stroke & $20(6)$ & $15(4)$ & $17(5)$ & .649 \\
\hline History of TIA & $18(5)$ & $16(5)$ & $13(4)$ & .634 \\
\hline Any cerebrovascular disease & $39(12)$ & $34(10)$ & $29(8)$ & .423 \\
\hline History of chronic renal disease & $38(11)$ & $32(9)$ & $33(10)$ & .676 \\
\hline COPD & $52(15)$ & $45(13)$ & $30(9)$ & .028 \\
\hline Connective tissue disorder $\dagger$ & $18(5)$ & $12(3)$ & $15(4)$ & .777 \\
\hline \multicolumn{5}{|l|}{ Thoracic aortic pathology, $(\%) \ddagger$} \\
\hline Aortic aneurysm & $290(86)$ & $294(85)$ & $316(92)$ & .005 \\
\hline Aortic dissection & $86(25)$ & $84(24)$ & $58(17)$ & .013 \\
\hline Aortic rupture & $15(4)$ & $9(3)$ & $8(2)$ & .251 \\
\hline Maximum aortic diameter, $\mathrm{mm}$, mean $\pm \mathrm{SD}$ & $56 \pm 11$ & $54 \pm 10$ & $54 \pm 10$ & .002 \\
\hline \multicolumn{5}{|l|}{ Aortic valve pathology, $(\%) \ddagger$} \\
\hline Aortic stenosis & $89(26)$ & $98(28)$ & $101(30)$ & .627 \\
\hline Aortic insufficiency§ & $50(15)$ & $54(16)$ & $96(28)$ & $<.001$ \\
\hline Morphology, $(\%)$ & & & & .752 \\
\hline Tricuspid & $220(65)$ & $234(69)$ & $226(67)$ & \\
\hline Bicuspid & $115(34)$ & $98(29)$ & $108(32)$ & \\
\hline Unicuspid & $2(1)$ & $6(2)$ & $4(1)$ & \\
\hline Presentation status, $(\%)$ & & & & .044 \\
\hline Elective & 237 (70) & $262(76)$ & $274(80)$ & \\
\hline Urgent & $31(9)$ & $21(6)$ & $31(9)$ & \\
\hline Emergent & $64(19)$ & $58(17)$ & $33(10)$ & \\
\hline Salvage & $7(2)$ & $3(1)$ & $4(1)$ & \\
\hline
\end{tabular}

$S D$, Standard deviation; NYHA, New York Heart Association; $L V E F$, left ventricular ejection fraction; TIA, transient ischemic attack; COPD, chronic obstructive pulmonary disease. *Continuous variables were compared using analysis of variance. Categorical variables were compared using Pearson $\chi^{2}$ test or Fisher exact test, as appropriate. $\dagger$ Genetically confirmed. ‡Not mutually exclusive. §Greater than mild. 
TABLE E3. Baseline patient characteristics for each surgeon

\begin{tabular}{|c|c|c|c|c|c|c|c|c|c|}
\hline & $\begin{array}{c}\text { Surgeon A } \\
(\mathbf{n}=155)\end{array}$ & $\begin{array}{l}\text { Surgeon B } \\
(\mathbf{n}=90)\end{array}$ & $\begin{array}{r}\text { Surgeon C } \\
(\mathrm{n}=174)\end{array}$ & $\begin{array}{c}\text { Surgeon D } \\
(n=94)\end{array}$ & $\begin{array}{c}\text { Surgeon E } \\
(\mathbf{n}=\mathbf{7 0})\end{array}$ & $\begin{array}{r}\text { Surgeon } F \\
(\mathbf{n}=239)\end{array}$ & $\begin{array}{c}\text { Surgeon G } \\
(\mathbf{n}=\mathbf{5 9})\end{array}$ & $\begin{array}{c}\text { Surgeon } H \\
(\mathrm{n}=144)\end{array}$ & $\begin{array}{c}P \\
\text { value }\end{array}$ \\
\hline Age, $y$, mean \pm SD & $63 \pm 13$ & $63 \pm 13$ & $64 \pm 14$ & $56 \pm 16$ & $65 \pm 14$ & $61 \pm 12$ & $63 \pm 14$ & $64 \pm 11$ & $<.001$ \\
\hline Female sex & $46(30 \%)$ & $26(29 \%)$ & $58(33 \%)$ & $28(30 \%)$ & $27(39 \%)$ & $62(26 \%)$ & $22(37 \%)$ & $32(22 \%)$ & .150 \\
\hline $\begin{array}{l}\text { Body mass index, } \mathrm{kg} / \mathrm{m}^{2} \text {, } \\
\quad \text { mean } \pm \mathrm{SD}\end{array}$ & $27 \pm 5$ & $28 \pm 5$ & $28 \pm 5$ & $29 \pm 6$ & $29 \pm 7$ & $29 \pm 5$ & $30 \pm 6$ & $28 \pm 5$ & .026 \\
\hline NYHA class III or IV & $42(27 \%)$ & $19(21 \%)$ & $40(23 \%)$ & $16(17 \%)$ & $0(0 \%)$ & $73(31 \%)$ & $9(15 \%)$ & $45(31 \%)$ & .053 \\
\hline LVEF $<40 \%$ & $6(4 \%)$ & $6(7 \%)$ & $15(9 \%)$ & $0(0 \%)$ & $1(1 \%)$ & $20(8 \%)$ & $2(3 \%)$ & $10(7 \%)$ & .383 \\
\hline Previous cardiac surgery & $34(22 \%)$ & $12(13 \%)$ & $20(11 \%)$ & $12(13 \%)$ & $17(24 \%)$ & $29(12 \%)$ & $9(15 \%)$ & $18(13 \%)$ & .039 \\
\hline \multicolumn{10}{|l|}{ Risk factors, $(\%)$} \\
\hline Smoking & $33(21)$ & $19(21)$ & $81(47)$ & $31(33)$ & $31(44)$ & $110(46)$ & $29(49)$ & $74(51)$ & $<.001$ \\
\hline Hypertension & $95(61)$ & $57(63)$ & $123(71)$ & $53(56)$ & $52(74)$ & $186(78)$ & $41(69)$ & $103(72)$ & .002 \\
\hline Diabetes mellitus & $13(8)$ & $11(12)$ & $17(10)$ & $8(9)$ & $9(13)$ & $28(12)$ & $9(15)$ & $19(13)$ & .763 \\
\hline Dyslipidemia & $103(66)$ & $58(64)$ & $79(45)$ & $43(46)$ & $22(32)$ & $100(42)$ & $28(47)$ & $68(47)$ & $<.001$ \\
\hline \multicolumn{10}{|l|}{ Comorbidities, $(\%)$} \\
\hline Coronary artery disease & $46(30)$ & $18(20)$ & $27(16)$ & $19(20)$ & $19(27)$ & $45(19)$ & $13(22)$ & $35(24)$ & .079 \\
\hline Previous myocardial infarction & $17(11)$ & $3(3)$ & $7(4)$ & $4(4)$ & $4(6)$ & $19(8)$ & $0(0)$ & $18(13)$ & .052 \\
\hline Congestive heart failure & $5(3)$ & $4(4)$ & $15(9)$ & $3(3)$ & $0(0)$ & $20(8)$ & $16(27)$ & $29(20)$ & $<.001$ \\
\hline Atrial fibrillation & $25(16)$ & $9(10)$ & $27(16)$ & $9(10)$ & $8(11)$ & $25(10)$ & 9 (19) & $24(17)$ & .31 \\
\hline Peripheral vascular disease & $23(15)$ & $12(13)$ & $19(11)$ & $7(7)$ & $8(11)$ & $10(4)$ & $5(8)$ & $16(11)$ & .043 \\
\hline History of stroke & $15(10)$ & $6(7)$ & $11(6)$ & $3(3)$ & $0(0)$ & $9(4)$ & $0(0)$ & $8(6)$ & .419 \\
\hline History of TIA & $6(4)$ & $2(2)$ & $13(7)$ & $4(4)$ & $0(0)$ & $4(2)$ & $6(10)$ & $12(8)$ & .044 \\
\hline Any cerebrovascular disease & $21(14)$ & $8(9)$ & $24(14)$ & $7(7)$ & $4(6)$ & $13(5)$ & $5(8)$ & $20(14)$ & .042 \\
\hline History of chronic renal disease & $24(15)$ & $18(20)$ & $5(3)$ & $9(10)$ & $6(9)$ & $4(2)$ & $2(3)$ & $35(24)$ & $<.001$ \\
\hline COPD & $24(15)$ & $8(9)$ & $23(13)$ & $9(10)$ & $5(7)$ & $18(8)$ & $11(19)$ & $29(20)$ & .007 \\
\hline Connective tissue disorder* & $2(1)$ & $0(0)$ & $10(6)$ & $6(6)$ & $2(3)$ & $4(2)$ & $8(14)$ & $13(9)$ & .005 \\
\hline \multicolumn{10}{|l|}{ Thoracic aortic pathology, $(\%) \dagger$} \\
\hline Aortic aneurysm & $136(88)$ & $83(92)$ & $139(80)$ & $82(87)$ & $65(93)$ & $208(87)$ & $51(86)$ & $136(94)$ & .010 \\
\hline Aortic dissection & $41(26)$ & $23(26)$ & $29(17)$ & $21(22)$ & $24(34)$ & $34(14)$ & $19(32)$ & $37(26)$ & .001 \\
\hline Aortic rupture & $5(3)$ & $3(3)$ & $8(5)$ & $0(0)$ & $2(3)$ & $7(3)$ & $1(2)$ & $6(4)$ & .974 \\
\hline $\begin{array}{l}\text { Maximum aortic diameter, } \\
\quad \mathrm{mm}, \text { mean } \pm \mathrm{SD}\end{array}$ & $57 \pm 13$ & $55 \pm 10$ & $55 \pm 10$ & $52 \pm 9$ & $57 \pm 11$ & $55 \pm 8$ & $56 \pm 9$ & $51 \pm 10$ & $<.001$ \\
\hline \multicolumn{10}{|l|}{ Aortic valve pathology, $(\%) \dagger$} \\
\hline Aortic stenosis & $25(16)$ & $21(23)$ & $47(27)$ & $31(33)$ & $8(11)$ & $83(35)$ & $22(37)$ & $51(35)$ & $<.001$ \\
\hline Aortic insufficiency $\ddagger$ & $101(65)$ & $58(64)$ & $23(13)$ & $0(0)$ & $0(0)$ & $0(0)$ & $17(29)$ & $1(1)$ & $<.001$ \\
\hline Morphology & & & & & & & & & $<.001$ \\
\hline Tricuspid & $116(75)$ & $64(71)$ & $111(64)$ & $59(63)$ & $52(81)$ & $146(61)$ & $33(61)$ & $99(69)$ & \\
\hline Bicuspid & $38(25)$ & $26(29)$ & $54(31)$ & $35(37)$ & $12(19)$ & $90(38)$ & $21(39)$ & $45(31)$ & \\
\hline Unicuspid & $0(0)$ & $0(0)$ & $9(5)$ & $0(0)$ & $0(0)$ & $3(1)$ & $0(0)$ & $0(0)$ & \\
\hline Presentation status, $(\%)$ & & & & & & & & & $<.001$ \\
\hline Elective & $128(83)$ & $69(77)$ & $125(72)$ & $69(73)$ & $43(61)$ & $212(89)$ & $36(61)$ & $91(63)$ & \\
\hline Urgent & $6(4)$ & $7(8)$ & $22(13)$ & $2(2)$ & $8(11)$ & $8(3)$ & $8(14)$ & $22(15)$ & \\
\hline Emergent & $20(13)$ & $12(13)$ & $21(12)$ & $23(24)$ & $19(27)$ & $18(8)$ & $15(25)$ & $27(19)$ & \\
\hline Salvage & $1(1)$ & $2(2)$ & $6(3)$ & $0(0)$ & $0(0)$ & $1(0)$ & $0(0)$ & $4(3)$ & \\
\hline
\end{tabular}

$S D$, Standard deviation; NYHA, New York Heart Association; $L V E F$, left ventricular ejection fraction; TIA, transient ischemic attack; COPD, chronic obstructive pulmonary disease. *Genetically confirmed. †Not mutually exclusive. $₫$ Greater than mild. 
TABLE E4. Operative details in each period

\begin{tabular}{|c|c|c|c|c|}
\hline & First third $(n=339)$ & Second third $(n=344)$ & Third third $(n=342)$ & $P$ value* \\
\hline \multicolumn{5}{|l|}{ Thoracic aortic procedure, $(\%) \dagger$} \\
\hline Hemiarch replacement & $272(80)$ & $269(78)$ & $277(81)$ & .638 \\
\hline Total arch replacement & $66(19)$ & $72(21)$ & $63(18)$ & .710 \\
\hline Elephant trunk & $43(13)$ & $40(12)$ & $51(15)$ & .437 \\
\hline \multicolumn{5}{|l|}{ Aortic valve and/or root procedure, $(\%) \dagger$} \\
\hline Aortic valve replacement & $56(17)$ & $49(14)$ & $73(21)$ & .045 \\
\hline Biological & $34(10)$ & $38(11)$ & $57(17)$ & \\
\hline Mechanical & $22(6)$ & $11(3)$ & $16(5)$ & \\
\hline Bentall procedure & $115(34)$ & $122(35)$ & $96(28)$ & .089 \\
\hline Biological & $61(18)$ & $72(21)$ & $66(19)$ & \\
\hline Mechanical & $54(16)$ & $50(15)$ & $30(9)$ & \\
\hline Aortic valve repair & $67(20)$ & $71(21)$ & $61(18)$ & .643 \\
\hline Valve-sparing root replacement & $27(8)$ & $42(12)$ & $55(16)$ & .005 \\
\hline Ross procedure & $7(2)$ & $10(3)$ & $16(5)$ & .159 \\
\hline Sinus root repair & $27(8)$ & $19(6)$ & $34(10)$ & .096 \\
\hline \multicolumn{5}{|l|}{ Concomitant procedures, $(\%) \dagger$} \\
\hline CABG & $61(18)$ & $71(21)$ & $71(21)$ & .597 \\
\hline Mitral valve repair & $7(2)$ & $7(2)$ & $11(3)$ & .533 \\
\hline Mitral valve replacement & $6(2)$ & $2(1)$ & $5(1)$ & .329 \\
\hline ASD/VSD repair & $7(2)$ & $1(0)$ & $4(1)$ & .075 \\
\hline Other concomitant procedures & $26(8)$ & $34(10)$ & $29(8)$ & .591 \\
\hline \multicolumn{5}{|l|}{ Arterial cannulation, $(\%) \dagger$} \\
\hline Femoral & $28(8)$ & $19(6)$ & $17(5)$ & .171 \\
\hline Axillary & $241(72)$ & $180(52)$ & $129(38)$ & $<.001$ \\
\hline Innominate & $48(14)$ & $108(31)$ & $155(46)$ & $<.001$ \\
\hline Carotid & 0 & $3(1)$ & $4(1)$ & .156 \\
\hline Distal arch & $48(14)$ & $47(14)$ & $62(18)$ & .206 \\
\hline Elephant trunk graft & $12(4)$ & $59(17)$ & $54(16)$ & $<.001$ \\
\hline \multicolumn{5}{|l|}{ Perfusion details } \\
\hline CPB time, min, median [IQR] & $166[129,219]$ & $168[130,225]$ & $165[121,214]$ & .183 \\
\hline Aortic crossclamp time, min, median [IQR] & $110[78,155]$ & $123[80,166]$ & $116[85,168]$ & .150 \\
\hline HCA duration, min, median [IQR] & $20[14,31]$ & $21[14,31]$ & $20[11,26]$ & .029 \\
\hline Long HCA duration ( $>40 \mathrm{~min}$ ) & $54(16 \%)$ & $49(14 \%)$ & $42(12 \%)$ & .393 \\
\hline HCA lowest temperature, ${ }^{\circ} \mathrm{C}$, median $[\mathrm{IQR}]$ & $20[18,24]$ & $25[22,26]$ & $25[24,27]$ & $<.001$ \\
\hline Cerebral perfusion, $(\%)$ & & & & .008 \\
\hline None & $38(11)$ & $25(7)$ & $35(10)$ & \\
\hline Antegrade & $291(86)$ & $317(92)$ & $301(88)$ & \\
\hline Retrograde & $10(3)$ & $2(1)$ & $6(2)$ & \\
\hline
\end{tabular}

$C A B G$, Coronary artery bypass grafting; $A S D$, atrial septal defect; $V S D$, ventricular septal defect; $C P B$, cardiopulmonary bypass; $I Q R$, interquartile range; $H C A$, hypothermic circulatory arrest. *Continuous variables were compared using analysis of variance. Categorical variables were compared using Pearson's $\chi^{2}$ test or Fisher exact test, as appropriate. Boldface denotes statistically significant $P$ values. †ंNot mutually exclusive. 
TABLE E5. Operative details for each surgeon

\begin{tabular}{|c|c|c|c|c|c|c|c|c|c|}
\hline & $\begin{array}{c}\text { Surgeon A } \\
(\mathbf{n}=155)\end{array}$ & $\begin{array}{c}\text { Surgeon B } \\
(\mathbf{n}=90)\end{array}$ & $\begin{array}{c}\text { Surgeon } C \\
(n=174)\end{array}$ & $\begin{array}{l}\text { Surgeon D } \\
(\mathrm{n}=94)\end{array}$ & $\begin{array}{c}\text { Surgeon E } \\
(\mathbf{n}=\mathbf{7 0})\end{array}$ & $\begin{array}{c}\text { Surgeon } F \\
(n=239)\end{array}$ & $\begin{array}{l}\text { Surgeon } \mathbf{G} \\
(\mathbf{n}=\mathbf{5 9})\end{array}$ & $\begin{array}{c}\text { Surgeon } H \\
(n=144)\end{array}$ & $\begin{array}{c}P \\
\text { value }\end{array}$ \\
\hline \multicolumn{10}{|l|}{ Thoracic aortic procedure, $(\%)^{*}$} \\
\hline Hemiarch replacement & $110(71)$ & $84(93)$ & $115(66)$ & $90(96)$ & $59(84)$ & $199(83)$ & $49(83)$ & $112(78)$ & $<.001$ \\
\hline Total arch replacement & $43(28)$ & $6(7)$ & $59(34)$ & $3(3)$ & $12(17)$ & $38(16)$ & $11(19)$ & $29(20)$ & $<.001$ \\
\hline Elephant trunk & $30(19)$ & $2(2)$ & $42(24)$ & $1(1)$ & $4(6)$ & $32(13)$ & $10(17)$ & $13(9)$ & $<.001$ \\
\hline \multicolumn{10}{|l|}{$\begin{array}{l}\text { Aortic valve and/or root } \\
\text { procedure, }(\%)^{*}\end{array}$} \\
\hline Aortic valve replacement & $34(22)$ & $31(34)$ & $9(5)$ & $10(11)$ & $7(10)$ & $57(24)$ & $11(19)$ & $19(13)$ & $<.001$ \\
\hline Biological & $27(17)$ & $20(22)$ & $8(5)$ & $8(9)$ & $5(7)$ & $40(17)$ & $8(14)$ & $13(9)$ & \\
\hline Mechanical & $7(5)$ & $11(12)$ & $1(1)$ & $2(2)$ & $2(3)$ & $17(7)$ & $3(5)$ & $6(4)$ & \\
\hline Bentall procedure & $51(33)$ & $17(19)$ & $72(41)$ & $19(20)$ & $7(10)$ & $75(31)$ & $16(27)$ & $76(53)$ & $<.001$ \\
\hline Biological & $22(14)$ & $7(8)$ & $50(29)$ & $17(18)$ & $3(4)$ & $40(17)$ & $9(15)$ & $51(35)$ & \\
\hline Mechanical & $29(19)$ & $10(11)$ & $22(13)$ & $2(2)$ & $4(6)$ & $35(15)$ & $7(12)$ & $25(17)$ & \\
\hline Aortic valve repair & $34(22)$ & $29(32)$ & $30(17)$ & $21(22)$ & $38(54)$ & $20(8)$ & $5(8)$ & $22(15)$ & $<.001$ \\
\hline $\begin{array}{l}\text { Valve-sparing root } \\
\text { replacement }\end{array}$ & $15(10)$ & $0(0)$ & $41(24)$ & $14(15)$ & $13(19)$ & $27(11)$ & $4(7)$ & $10(7)$ & $<.001$ \\
\hline Ross procedure & $0(0)$ & $0(0)$ & $6(3)$ & $21(22)$ & $0(0)$ & $6(3)$ & $0(0)$ & $0(0)$ & $<.001$ \\
\hline Sinus root repair & $11(7)$ & $11(12)$ & $25(14)$ & $1(1)$ & $1(1)$ & $11(5)$ & $10(17)$ & $10(7)$ & $<.001$ \\
\hline \multicolumn{10}{|l|}{ Concomitant procedures, $(\%)^{*}$} \\
\hline CABG & $50(32)$ & $18(20)$ & $26(15)$ & $9(10)$ & $8(11)$ & $44(18)$ & $9(15)$ & $39(27)$ & $<.001$ \\
\hline Mitral valve repair & $7(5)$ & $4(4)$ & $1(1)$ & $1(1)$ & $0(0)$ & $4(2)$ & $0(0)$ & $8(6)$ & .216 \\
\hline Mitral valve replacement & $4(3)$ & $0(0)$ & $4(2)$ & $2(2)$ & $2(3)$ & $1(0)$ & $0(0)$ & $0(0)$ & .880 \\
\hline ASD/VSD repair & $1(1)$ & $1(1)$ & $2(1)$ & $1(1)$ & $2(3)$ & $2(1)$ & $1(2)$ & $2(1)$ & .940 \\
\hline $\begin{array}{l}\text { Other concomitant } \\
\text { procedures }\end{array}$ & $32(21)$ & $13(14)$ & $13(7)$ & $1(1)$ & $6(9)$ & $9(4)$ & $2(3)$ & $13(9)$ & $<.01$ \\
\hline \multicolumn{10}{|l|}{ Arterial cannulation, $(\%)^{*}$} \\
\hline Femoral & $13(8)$ & $7(8)$ & $12(7)$ & $2(2)$ & $8(11)$ & $16(7)$ & $4(7)$ & $2(1)$ & .129 \\
\hline Axillary & $101(66)$ & $57(63)$ & $121(70)$ & $17(18)$ & $61(87)$ & $87(36)$ & $9(16)$ & $97(67)$ & $<.001$ \\
\hline Innominate & $18(12)$ & $13(14)$ & $49(28)$ & $13(14)$ & $0(0)$ & $138(58)$ & $37(66)$ & $43(30)$ & $<.001$ \\
\hline Carotid & $2(1)$ & $0(0)$ & $2(1)$ & $0(0)$ & $0(0)$ & $2(1)$ & $1(2)$ & $0(0)$ & 1.000 \\
\hline Distal arch & $56(36)$ & $26(29)$ & $1(1)$ & $62(66)$ & $1(1)$ & $1(0)$ & 7 (13) & $3(2)$ & $<.001$ \\
\hline Elephant trunk graft & $0(0)$ & $0(0)$ & $112(64)$ & $13(14)$ & $0(0)$ & $0(0)$ & $0(0)$ & $0(0)$ & $<.001$ \\
\hline \multicolumn{10}{|l|}{ Perfusion details } \\
\hline $\begin{array}{l}\text { CPB time, min, } \\
\text { median [IQR] }\end{array}$ & $\begin{array}{c}127 \\
{[101,167]}\end{array}$ & $\begin{array}{c}132 \\
{[108,168]}\end{array}$ & $\begin{array}{c}231 \\
{[191,277]}\end{array}$ & $\begin{array}{c}171 \\
{[123,211]}\end{array}$ & $\begin{array}{c}170 \\
{[125,235]}\end{array}$ & $\begin{array}{c}155 \\
{[130,200]}\end{array}$ & $\begin{array}{c}160 \\
{[134,192]}\end{array}$ & $\begin{array}{c}180 \\
{[140,242]}\end{array}$ & $<.001$ \\
\hline $\begin{array}{c}\text { Aortic crossclamp time, } \\
\text { min, median [IQR] }\end{array}$ & $\begin{array}{c}83 \\
{[59,105]}\end{array}$ & $\begin{array}{c}91 \\
{[66,112]}\end{array}$ & $\begin{array}{c}167 \\
{[124,216]}\end{array}$ & $\begin{array}{c}131 \\
{[87,176]}\end{array}$ & $\begin{array}{c}102 \\
{[74,151]}\end{array}$ & $\begin{array}{c}121 \\
{[86,154]}\end{array}$ & $\begin{array}{c}111 \\
{[70,143]}\end{array}$ & $\begin{array}{c}141 \\
{[102,187]}\end{array}$ & $<.001$ \\
\hline $\begin{array}{l}\text { HCA duration, min, } \\
\text { median }[\mathrm{IQR}]\end{array}$ & $9[6,17]$ & $12[10,15]$ & $29[23,42]$ & $13[10,17]$ & $22[16,32]$ & $20[18,26]$ & $17[12,22]$ & $20[15,42]$ & $<.001$ \\
\hline $\begin{array}{l}\text { Long HCA duration } \\
\qquad(>40 \mathrm{~min})\end{array}$ & $9(6 \%)$ & $2(2 \%)$ & $45(26 \%)$ & $5(5 \%)$ & $2(3 \%)$ & $37(15 \%)$ & $8(14 \%)$ & $37(26 \%)$ & $<.001$ \\
\hline $\begin{array}{l}\text { HCA lowest temperature, } \\
{ }^{\circ} \mathrm{C} \text {, median }[\mathrm{IQR}]\end{array}$ & $20[17,24]$ & $23[19,25]$ & $25[25,26]$ & $25[20,26]$ & $22[19,34]$ & $24[20,26]$ & $24[24,26]$ & $25[18,28]$ & $<.001$ \\
\hline Cerebral perfusion, $(\%)$ & & & & & & & & & $<.001$ \\
\hline None & $12(8)$ & $10(11)$ & $0(0)$ & $68(72)$ & $2(3)$ & $1(0)$ & $2(3)$ & $3(2)$ & \\
\hline Antegrade & $134(86)$ & $79(88)$ & $174(100)$ & $26(28)$ & $68(97)$ & $238(100)$ & $50(85)$ & $140(97)$ & \\
\hline Retrograde & $9(6)$ & $1(1)$ & $0(0)$ & $0(0)$ & $0(0)$ & $0(0)$ & $7(12)$ & $1(1)$ & \\
\hline
\end{tabular}

$C A B G$, Coronary artery bypass grafting; $A S D$, atrial septal defect; $V S D$, ventricular septal defect; $C P B$, cardiopulmonary bypass; $I Q R$, interquartile range; $H C A$, hypothermic circulatory arrest. *Not mutually exclusive. 
TABLE E6. Perioperative outcomes in each period

\begin{tabular}{|c|c|c|c|c|}
\hline & First third $(n=339)$ & Second third $(n=344)$ & Third third $(\mathrm{n}=342)$ & $P$ value* \\
\hline \multicolumn{5}{|l|}{ Primary safety outcome, $(\%)$} \\
\hline$\geq 1$ major complications $\dagger$ & $87(26)$ & $78(23)$ & $56(16)$ & .010 \\
\hline In-hospital or $30-\mathrm{d}$ mortality & $22(6)$ & $16(5)$ & $16(5)$ & .495 \\
\hline Stroke & $14(4)$ & $22(6)$ & $8(2)$ & .035 \\
\hline Reoperation for bleeding & $36(11)$ & $27(8)$ & $24(7)$ & .222 \\
\hline Dialysis-dependent renal failure & $12(4)$ & $17(5)$ & $7(2)$ & .122 \\
\hline$>40 \mathrm{~h}$ of mechanical ventilation & $48(14)$ & $39(11)$ & $20(6)$ & .001 \\
\hline Sternal dehiscence/mediastinitis & $6(2)$ & $2(1)$ & $2(1)$ & .196 \\
\hline \multicolumn{5}{|l|}{ Other adverse events, $(\%)$} \\
\hline Myocardial infarction & $3(1)$ & $3(1)$ & $9(3)$ & .114 \\
\hline Postoperative IABP requirement & $2(1)$ & 0 & 0 & .109 \\
\hline Postoperative atrial fibrillation & $137(41)$ & $133(39)$ & $105(31)$ & .017 \\
\hline Cardiac arrest/malignant arrhythmia & $13(4)$ & $5(1)$ & $12(4)$ & .108 \\
\hline Spinal cord injury & $4(1)$ & $4(1)$ & $1(0)$ & .379 \\
\hline Transient ischemic attack & $5(2)$ & $11(3)$ & $2(1)$ & .034 \\
\hline Delirium & $66(19)$ & $83(24)$ & $49(14)$ & .005 \\
\hline Septic shock & $7(2)$ & $4(1)$ & $3(1)$ & .392 \\
\hline \multicolumn{5}{|l|}{ Blood product transfusion, $(\%)$} \\
\hline Packed red blood cells & $150(44)$ & $116(34)$ & $86(25)$ & $<.001$ \\
\hline Fresh-frozen plasma & $196(58)$ & $125(36)$ & $120(35)$ & $<.001$ \\
\hline Platelets & $190(56)$ & $147(43)$ & $121(35)$ & $<.001$ \\
\hline Factor VII & $29(9)$ & $19(6)$ & $14(4)$ & .048 \\
\hline ICU length of stay, $d$, median [IQR] & $2[1,5]$ & $2[1,4]$ & $2[1,3]$ & .002 \\
\hline ICU length of stay $\geq 4 \mathrm{~d}$ & $112(33 \%)$ & $87(25 \%)$ & $73(21 \%)$ & .002 \\
\hline Hospital length of stay, d, median [IQR] & $8[6,13]$ & $7[5,11]$ & $7[5,10]$ & .006 \\
\hline
\end{tabular}


TABLE E7. Perioperative outcomes for each surgeon

\begin{tabular}{|c|c|c|c|c|c|c|c|c|c|}
\hline & $\begin{array}{c}\text { Surgeon } A \\
(n=155)\end{array}$ & $\begin{array}{c}\text { Surgeon B } \\
(\mathbf{n}=90)\end{array}$ & $\begin{array}{c}\text { Surgeon } C \\
(n=174)\end{array}$ & $\begin{array}{c}\text { Surgeon D } \\
(n=94)\end{array}$ & $\begin{array}{l}\text { Surgeon } E \\
(\mathbf{n}=70)\end{array}$ & $\begin{array}{c}\text { Surgeon } F \\
(n=239)\end{array}$ & $\begin{array}{l}\text { Surgeon G } \\
(\mathbf{n}=\mathbf{5 9})\end{array}$ & $\begin{array}{c}\text { Surgeon } H \\
(n=144)\end{array}$ & $\begin{array}{c}P \\
\text { value }\end{array}$ \\
\hline \multicolumn{10}{|l|}{ Primary safety endpoint, (\%) } \\
\hline$\geq 1$ major complications* & $32(21)$ & $19(21)$ & $33(19)$ & $24(26)$ & $17(24)$ & $36(15)$ & $10(17)$ & $50(35)$ & .002 \\
\hline In-hospital or 30-d mortality & $8(5)$ & $6(7)$ & $6(3)$ & $2(2)$ & $5(7)$ & $7(3)$ & $4(7)$ & $16(11)$ & .037 \\
\hline Stroke & $8(5)$ & $4(4)$ & $4(2)$ & $3(3)$ & $3(4)$ & $10(4)$ & $3(5)$ & $9(6)$ & .831 \\
\hline Reoperation for bleeding & $12(8)$ & $13(14)$ & $11(6)$ & $5(5)$ & $7(10)$ & $21(9)$ & $1(2)$ & $17(12)$ & .140 \\
\hline Dialysis-dependent renal failure & $3(2)$ & $1(1)$ & $3(2)$ & $10(11)$ & $6(9)$ & $5(2)$ & $3(5)$ & $5(3)$ & .004 \\
\hline$>40 \mathrm{~h}$ of mechanical ventilation & $15(10)$ & $3(3)$ & $23(13)$ & $16(17)$ & $13(19)$ & $2(1)$ & $7(12)$ & $28(19)$ & $<.001$ \\
\hline Sternal dehiscence/mediastinitis & $0(0)$ & $0(0)$ & $2(1)$ & $1(1)$ & $1(1)$ & $1(0)$ & $0(0)$ & $5(3)$ & .647 \\
\hline \multicolumn{10}{|l|}{ Other adverse events, $(\%)$} \\
\hline Myocardial infarction & $5(3)$ & $2(2)$ & $0(0)$ & $1(1)$ & $0(0)$ & $1(0)$ & $2(3)$ & $4(3)$ & .710 \\
\hline Postoperative IABP requirement & $1(1)$ & $0(0)$ & $0(0)$ & $0(0)$ & $0(0)$ & $0(0)$ & $1(2)$ & $0(0)$ & .999 \\
\hline Postoperative atrial fibrillation & $70(45)$ & $45(50)$ & $39(22)$ & $37(39)$ & $36(55)$ & 77 (32) & $26(44)$ & $45(31)$ & $<.001$ \\
\hline $\begin{array}{l}\text { Cardiac arrest/malignant } \\
\text { arrhythmia }\end{array}$ & $4(3)$ & $1(1)$ & $3(2)$ & $2(2)$ & $4(6)$ & $7(3)$ & $1(2)$ & $8(6)$ & .407 \\
\hline Spinal cord injury & $2(1)$ & $3(3)$ & $3(2)$ & $0(0)$ & $0(0)$ & $1(0)$ & $0(0)$ & $0(0)$ & .826 \\
\hline Transient ischemic attack & $9(6)$ & $3(3)$ & $2(1)$ & $3(3)$ & $0(0)$ & $0(0)$ & $1(2)$ & $0(0)$ & .488 \\
\hline Delirium & $47(30)$ & $18(20)$ & $11(6)$ & $25(27)$ & $8(12)$ & $49(21)$ & $11(19)$ & $29(20)$ & $<.001$ \\
\hline Septic shock & $1(1)$ & $0(0)$ & $0(0)$ & $3(3)$ & $0(0)$ & $2(1)$ & $2(3)$ & $6(4)$ & .395 \\
\hline \multicolumn{10}{|l|}{ Blood product transfusion, $(\%)$} \\
\hline Packed red blood cells & $30(19)$ & $14(16)$ & $76(44)$ & $36(38)$ & $37(53)$ & $75(31)$ & $35(59)$ & $49(34)$ & $<.001$ \\
\hline Fresh-frozen plasma & $95(61)$ & $52(58)$ & $64(37)$ & $27(29)$ & $29(41)$ & $79(33)$ & $29(49)$ & $66(46)$ & $<.001$ \\
\hline Platelets & $113(73)$ & $61(68)$ & $57(33)$ & $33(35)$ & $33(47)$ & $79(33)$ & $39(66)$ & $43(30)$ & $<.001$ \\
\hline Factor VII & $1(1)$ & $1(1)$ & $18(10)$ & $4(4)$ & $4(6)$ & $22(9)$ & $11(19)$ & $1(1)$ & $<.001$ \\
\hline $\begin{array}{l}\text { ICU length of stay, } d, \\
\text { median [IQR] }\end{array}$ & $3[1,5]$ & $1[1,3]$ & $1[1,3]$ & $2[2,5]$ & $2[1,5]$ & $1[1,3]$ & $2[1,4]$ & $2[1,4]$ & $<.001$ \\
\hline ICU length of stay $\geq 4 \mathrm{~d}$ & $47(30 \%)$ & $13(14 \%)$ & $40(23 \%)$ & $31(33 \%)$ & $22(31 \%)$ & $58(24 \%)$ & $13(22 \%)$ & $48(33 \%)$ & .25 \\
\hline $\begin{array}{l}\text { Hospital length of stay, } d, \\
\text { median [IQR] }\end{array}$ & $8[6,11]$ & $7[5,10]$ & $8[6,13]$ & $7[5,10]$ & $10[6,15]$ & $7[5,10]$ & $8[6,13]$ & $8[5,12]$ & .011 \\
\hline
\end{tabular}

$I A B P$, Intra-aortic balloon pump; $I C U$, intensive care unit; $I Q R$, interquartile range. *Major complications defined as the occurrence of at least 1 of the following: death, stroke, bleeding requiring reintervention, acute renal failure requiring dialysis, long duration of postoperative mechanical ventilation ( $>40$ hours), and sternal dehiscence/mediastinitis. 
TABLE E8. List of members of the Canadian Thoracic Aortic Collaborative

\begin{tabular}{|c|c|c|}
\hline Name & Institution & City \\
\hline Chu, Michael W.A. & Western University & London, ON \\
\hline Adams, Corey & Memorial University & St. John's, NL \\
\hline Atoui, Rony & Northern Ontario School of Medicine (NOSM) & Sudbury, ON \\
\hline Appoo, Jehangir & University of Calgary & Calgary, $\mathrm{AB}$ \\
\hline Bittira, Bindu & Sudbury Regional Hospital-Memorial Site & Sudbury, ON \\
\hline Boodhwani, Munir & University of Ottawa & Ottawa, ON \\
\hline Bouhout, Ismail & University of Montreal & Montreal, QC \\
\hline Bozinovski, John & Royal Jubilee Hospital & Victoria, BC \\
\hline Cartier, Raymond & University of Montreal & Montreal, QC \\
\hline Chung, Jennifer & University of Toronto & Toronto, ON \\
\hline Cutrara, Charles & U of Toronto (Trillium) & Mississauga, ON \\
\hline Dagenais, Francois & Laval University & Quebec City, QC \\
\hline Demers, Phillipe & University of Montreal & Montreal, QC \\
\hline Dumont, Eric & Laval University & Quebec City, QC \\
\hline El-Hamamsy, Ismail & University of Montreal & Montreal, QC \\
\hline Fedak, Paul & University of Calgary & Calgary, AB \\
\hline Ghoneim, Aly & McGill University & Montreal, QC \\
\hline Guo, Ray & Western University & London, ON \\
\hline Hassan, Ansar & Saint John Regional Hospital & St. John, NB \\
\hline Herman, Christine & Dalhousie University & Halifax, NS \\
\hline Kumar, Kanwal & University of Manitoba & Winnipeg, MB \\
\hline Lachapelle, Kevin & McGill University & Montreal, QC \\
\hline Lodewyks, Carly & University of Manitoba & Winnipeg, MB \\
\hline MacArthur, Roderick & University of Alberta & Edmonton, $\mathrm{AB}$ \\
\hline Mazine, Amine & University of Toronto & Toronto, ON \\
\hline McClure, Scott & University of Calgary & Calgary, $\mathrm{AB}$ \\
\hline Moon, Michael & University of Alberta & Edmonton, $\mathrm{AB}$ \\
\hline Ouzounian, Maral & University of Toronto & Toronto, ON \\
\hline Payne, Darrin & Queens University & Kingston, ON \\
\hline Peterson, Mark & University of Toronto & Toronto, ON \\
\hline Poirier, Nancy & University of Montreal & Montreal, QC \\
\hline Poostizadeh, Ahmad & University of British Columbia & Kelowna, BC \\
\hline Pozeg, Zlatko & Saint John Regional Hospital & St. John, NB \\
\hline Salasidis, Gary & St. Mary's Hospital & Kitchener-Waterloo, ON \\
\hline Stevens, Louis-Mathieu & University of Montreal & Montreal, QC \\
\hline Tarola, Chris & Western University & London, ON \\
\hline Tsang, John & University of Saskatchewan & Regina, SK \\
\hline Valdis, Matt & Western University & London, ON \\
\hline Whitlock, Richard & McMaster University & Hamilton, ON \\
\hline Wong, Daniel & University of British Columbia & Vancouver, BC \\
\hline Wood, Jeremy & Dalhousie University & Halifax, NS \\
\hline Yamashita, Michael & University of Manitoba & Winnipeg, MB \\
\hline
\end{tabular}

